\title{
PERBEDAAN EFEKTIFITAS PIJAT PERINEUM DAN SUPERCROWNING TERHADAP DERAJAT RUPTUR PERINEUM PADA IBU BERSALIN PRIMIPARA
}

\author{
Lestari Puji Astuti, Sri Harmiati, Tri Ismu Pujianto \\ STIKes KaryaHusada Semarang, Prodi SarjanaTerapan Kebidanan,JI.Kompol R Soekanto No.46, Semarang \\ 085349854305 \\ tari_rozai@yahoo.co.id
}

\begin{abstract}
ABSTRAK
Ruptur perineum merupakan robekan pada perineum yang terjadi pada saat bayi lahir secara spontan maupun menggunakan alat atau tindakan. Ruptur perineum pada primipara terjadi karena kondisi perineum kaku, jalan lahir belum pernah dilewati oleh bayi. Upaya pencegahan ruptur perineum bisa dilakukan dengan cara pijat perineum dan supercrowning. Tujuan Penelitian untuk mengetahui perbedaan efektifitas pijat perineum dan supercrowning terhadap derajat ruptur perineum . Jenis penelitian adalah quasi experiment, desain penelitian menggunakan post-test only control group. Populasi Penelitian ini adalah ibu bersalin primipara di UPT Puskesmas Kragan II sebanyak 59 ibu bersalin. Sampel Penelitian ini adalah ibu bersalin primipara sebanyak 36 ibu bersalin dengan accidental sampling. Analisa data menggunakan Mann Whitney untuk melihat adanya perbedaan efektifitas pijat perineum dan supercrowning terhadap derajat ruptur perineum pada ibu bersalin primipara. Hasil penelitian nilai mean rank pada kelompok yang diberikan perlakuan pijat perineum 12,33 dan pada kelompok yang diberikan perlakuan supercrowning 24,67 dan nilai $p$-value $=0,000$ $(<0,05)$. Ada perbedaan efektifitas pijat perineum dan supercrowning terhadap derajat ruptur perineum pada ibu bersalin primipara. Pijat perineum lebih efektif mencegah derajat ruptur perineum pada ibu bersalin primipara.
\end{abstract}

Kata kunci: pijat perineum; supercrowning; ruptur perineum.

\section{EFFECTIVENESS DISTICNTION OF PERINEUM MASSAGE AND SUPERCROWNING TOWARDS DEGREE OF PERINEUM RUPTURES IN PRIMIPARA MOTHERS}

\begin{abstract}
Perineal rupture is a tear in the perineum that occurs when a baby is born spontaneously or uses tools or actions. Perineal ruptur in primipara occurs because of a rigid perineum, the birth canal has never been passed by the baby causing ruptur of the perineum. The efforts to prevent perineal rupture can be done by massaging the perineum and supercrowning. The purpose of this study was to determine the differences in the effectiveness of perineal massage and supercrowning on the level of perineal rupture. The type of research used is quasi experiment. The design of this study used a post-test only control group. The population of this research was 59 primiparous mothers in Kragan II Health Center. The sample of this research was 36 primiparous mothers. Sampling technique in this study used accidental sampling. Data analysis used Mann Whitney to see differences in the effectivness of perineum massage and supercrowning on the level of perineal ruptur in primiparaous mothers. Mean rank in the interventionof perineal massage is 12,33, while in supercrowning group is 24.67 and $p$-value $=0,000(<0.05)$. There is a difference in the effectiveness of perineum massage and supercrowning on the level of perineal rupture in primiparous mothers. From the results of this study the perineum massage is more effective in preventing the level of perineal rupture in primiparous maternal
\end{abstract}

Keywords: perineum massage; supercrowning; perineum rupture 


\section{LATAR BELAKANG}

Persalinan normal adalah proses pengeluaran hasil konsepsi yang dapat hidup dari dalam uterus melalui vagina ke dunia luar yang terjadi pada kehamilan yang cukup bulan (37-42 minggu) dengan ditandai adanya kontraksi uterus yang menyebabkan terjadinya penipisan, dilatasi serviks, dan mendorong janin keluar melalui jalan lahir dengan presentasi belakang kepala tanpa alat atau bantuan(lahir spontan) serta tidak ada komplikasi pada ibu dan janin (Eka Puspita, 2014).

Setiap persalinan beresiko mengalami komplikasi baik terhadap ibu maupun janin. Komplikasi yang tidak teratasi dapat menimbulkan kematian pada ibu dan kematian pada bayi. Beberapa indikator yang sering digunakan untuk mengetahui derajat kesehatan masyarakat adalah angka kematian ibu, angka kematian bayi, angka kematian balita dan angka harapan hidup.(Sadli, S. 2010)

Angka Kematian lbu (AKI) Pada tahun 2015 di dunia 216 per 100.000 kelahiran hidup, AKI di Negara berkembang 436 per 100.000 kelahiran hidup. AKI di Indonesia 126 per 100.000 kelahiran hidup (UNICEF, 2015).

Angka Kematian lbu di Provinsi Jawa Tengah tahun 2018 mencapai 78,60 per 100.000 kelahiran hidup atau menurun 9,98 persen dibanding tahun 2017 yaitu 88,58 per 100.000 kelahiran hidup. Penurunan AKI ini belum melampaui target Sustainable Development Goals (SDG's) yang menetapkan target 70 per 100.000 kelahiran hidup. (Profil Jateng, 2018)

Tingginya kasus kesakitan dan kematian ibu di banyak negara berkembang terutama disebabkanperdarahan, eklamsi, sepsis, dan komplikasi keguguran. Peristiwa dalam bidang kebidanan yang dapat menimbulkan perdarahan adalah gangguan pelepasan plasenta, atonia uteri dan perlukaan jalan lahir Perdarahan yang banyak dapat terjadi karena ruptur perineum selama proses persalinan baik secara spontan maupun dengan tindakan. Ada hubungan yang bermakna antara laserasi jalan lahir dengan terjadinya perdarahan post partum. Artinya ibu yang mengalami laserasi jalan lahir memiliki resiko perdarahan 29,8 kali dibandingkan dengan ibu yang tidak mengalami laserasi jalan lahir (Yuliawati Yetti Anggraini, 2013)

Kejadian ruptur perineum pada primigravida lebih banyak dibandingkan dengan multigravida. Hal ini disebabkan karena elastisitas perineum yang kurang dan perineum yang kaku. Jalan lahir pada primigravida belum pernah dilalui oleh janin yang menyebabkan vagina menjadi teregang pada waktu janin lahir sehingga terjadi rupture pada jalan lahir.( Rizsa Choirunnisa, 2019)

Ruptur perineum spontan adalah perlukaan jalan lahir atau robekan perineum secara tidak sengaja karena persalinan dan terjadi hampir pada semua persalinan pertama dan tidak jarang juga pada persalinan berikutnya. Ruptur perineum terjadi oleh beberapa faktoryaitu pengeluaran kepala yang mendadak cepat, ukuran bayi baru lahir yang berlebihan, dan jaringan ibu yang mudah robek/tidak elastis. (Reeder Sharon, 2012)

Pijat perineum merupakan salah satu cara yang bisa dilakukan untuk mencegah terjadinya ruptur perineum pada saat persalinan, karena keuntungan dari pijat perineum adalah menstimulasi aliran darah ke perineum yang akan membantu mempercepat proses penyembuhan setelah melahirkan, menghindari kejadian episiotomi atau robeknya perineum di kala melahirkan dengan meningkatkan elastisitas perineum, membantu ibu mengontrol diri saat mengejan, karena jalan eluar untuk bayi sudah disiapkan dengan baik.(Ishak, 2012)

Supercrowning merupakan salah satu alternative untuk mengurangi laserasi perineum pada kala dua persalinan. supercrowning merupakan suatu istilah dimana pas saat crowning terjadi diperpanjang, minimal satu menit atau sampai timbul satu atau dua kontraksi uterus. Tehnik ini membiarkan vagina dan perineum meregang perlahan-lahan di sekitar kepala janin yang mulai muncul, sehingga mencegah robekan akibat kelahiran kepala yang terlalu cepat. Saat terjadi peregangan, sensasi panas merupakan sinyal untuk menghentikan mengejan. (Surayniwaty, 2014) 
Studi pendahuluan yang dilakukan di UPT Puskesmas Kragan II bulan Mei - Juni 2019 didapatkan data jumlah ibu bersalin pada tahun 2018 sebanyak 248 orang, ibu bersalin yang mengalami ruptur perineum 236 orang (95\%). Derajat ruptur perineum yang mengakibatkan perdarahan yaitu ruptur perineum tingkat 3 dan tingkat 4 sebanyak 15 orang $(6,3 \%)$. Peneliti melakukan wawancara pada para bidan di UPT Puskesmas Kragan II, dari 10 ibu bersalin yang mengalami ruptur perineum, 3 orang ibu bersalin mengalami ruptur perineum tingkat 3 dan tingkat 4 (33,3\%). Ruptur perineum terjadi karena perineum yang kaku. Upaya yang sudah dilakukan untuk mengatasi masalah tersebut adalah dengan senam hamil, tetapi ruptur perineum masih sering terjadi. Oleh karenanya perlu upaya tambahan untuk menurunkan tingkat ruptur perineum yaitu dengan pijat perineum dan supercrowning.

Penelitian yang dilakukan Wewet Sawitri, dkk menunjukkan hasil bahwa terdapat pengaruh pemijatan perineum pada primigravida terhadap kejadian ruptur perineum dibandingkan dengan kelompok yang tidak dilakukan pemijatan perineum saat persalinan.

Hasil penelitian Surayniwaty, menunjukkan hasil bahwa kejadian rupture pada tehnik supercrowning lebih kecil dibandingkan tehnik standar Asuhan Persalinan Normal (APN).

Tujuan penelitian ini adalah untuk mengetahui perbedaan efektifitas pijat perineum dan supercrowning terhadap derajat ruptur perineum pada ibu bersalin primipara.

\section{METODE}

Penelitian dilaksanakan di UPT Puskesmas Kragan II, Kabupaten Rembang pada Juli s/d September 2019. Pemilihan tempat penelitian di UPT Puskesmas Kragan II adalah berdasarkan dari data persalinan 2018 sejumlah 248 persalinan yang mengalami ruptur 236 orang (95\%). Jenis penelitian ini adalah Kuantitatif. Desain penelitian menggunakan quasy experiment design post test only control group. Populasi penelitian ini adalah 59 ibu bersalin primipara. Sampel penelitian ini sebanyak 36 ibu bersalin primipara, yang terdiri dari 18 responden yang diberi perlakuan pijat perineum dan 18 responden yang diberi perlakuan supercrowning dengan accidental sampling. Kriteria inklusi adalah primipara yang bersedia menjadi responden, usia 20-35 tahun, usia kehamilan memasuki 36 minggu, merupakan persalinan normal, bersalin di UPT Puskesmas Kragan II. Kriteria ekslusi adalah ibu hamil dan ibu bersallin yang selama proses persalinan mengalami kondisi yang patologis. Intervensi pada penelitian ini yaitu pijat perineum yang diberikan pada ibu hamil mulai usia kehamilan 36 minggu sampai persalinan dimulai, dilakukan setiap minggu 5 kali dengan durasi selama 10 menit, menggunakan minyak VCO (Virgin Coconut Oil) dan supercrowning pada ibu bersalin kala II pada saat kepala bayi tampak di vulva 5-6 cm. Instrumen penelitian menggunakan lembar observasi, lembar rekap hasil observasi derajat ruptur perineum . Analisa bivariate dengan uji statistic Man Whitney. Etika dalam penelitian ini meliputi informed consent, anonymity dan confidentiality.

\section{HASIL}

Hasil penelitian tentang perbedaan efektifitas pijat perineum dan supercrowning terhadap derajat ruptur perineum pada ibu bersalin primipara di UPT Puskesmas Kragan II adalah sebagai berikut:

\section{Tabel 1 Karakteristik Responden Derajat ruptur perineum Setelah Dilakukan Pijat Perineum dan Supercrowning Pada Ibu Bersalin Primipara $(n=18)$}

\begin{tabular}{|c|c|c|c|c|c|}
\hline \multicolumn{2}{|c|}{$\begin{array}{l}\text { Karakteristik } \\
\text { Responden }\end{array}$} & \multicolumn{2}{|c|}{$\begin{array}{l}\text { Kelompok } \\
\text { Pijat } \\
\text { Perineum }\end{array}$} & \multicolumn{2}{|c|}{$\begin{array}{l}\text { Kelompok } \\
\text { Supercrow- } \\
\text { ning }\end{array}$} \\
\hline & & $f$ & $\%$ & $f$ & $\%$ \\
\hline $\begin{array}{l}\text { Umur } \\
\text { (tahun) }\end{array}$ & $20-25$ & 18 & 100 & 18 & 100 \\
\hline \multirow[t]{4}{*}{ Pekerjaan } & Ibu & & & & \\
\hline & $\begin{array}{l}\text { Rumah } \\
\text { Tangga }\end{array}$ & 7 & 38,9 & 17 & 94,4 \\
\hline & $\begin{array}{l}\text { Tidak } \\
\text { Bekerja }\end{array}$ & 0 & 0 & 1 & 5,6 \\
\hline & Bekerja & 11 & 61,1 & 0 & 0 \\
\hline \multirow[t]{2}{*}{ Pendidikan } & SMP & 12 & 66,6 & 15 & 83,3 \\
\hline & SMA & 6 & 33,4 & 3 & 16,7 \\
\hline
\end{tabular}


Tabel 1 menunjukkan bahwa semua responden pada kelompok pijat perineum sebagian besar berumur 20-25 tahun yaitu 18 orang $(100 \%)$, berdasarkan tingkat pendidikan responden paling banyak SMP 12 orang $(66,6 \%)$, pekerjaan responden mayoritas bekerja yaitu 11 orang $(61,1 \%)$. Pada kelompok supercrowning semua responden berumur 2025 tahun yaitu 18 orang $(100 \%)$, berdasarkan tingkat pendidikan responden paling banyak SMP 15 orang $(83,3 \%)$, pekerjaan responden mayoritas ibu rumah tangga yaitu 17 orang $(94,4 \%)$.

\section{Tabel 2 Distribusi Frekuensi Derajat ruptur perineum Setelah Dilakukan Pijat Perineum dan Supercrowning Pada Ibu Bersalin Primipara $(n=18)$}

\begin{tabular}{lcccc}
\hline Intervensi & Median & SD & Min & Max \\
\hline $\begin{array}{l}\text { Pijat } \\
\text { Perineum }\end{array}$ & 0.00 & .485 & 0 & 1 \\
$\begin{array}{l}\text { Supercrow- } \\
\text { ning }\end{array}$ & 1.00 & .669 & 0 & 2 \\
\hline
\end{tabular}

Tabel 2 menunjukkan hasil dari 18 responden dapat diketahui bahwa derajat ruptur perineum kelompok yang diberi perlakuan pijat perineum nilai median 0.00 dengan standar deviasinya 0.485 , derajat ruptur perineum terendah adalah 0 dan derajat ruptur perineum tertinggi adalah 1 . Derajat ruptur perineum dari 18 responden pada kelompok yang diberi perlakuan supercrowning nilai median adalah 1.00 dengan standar deviasi 0.669. Derajat ruptur perineum terendah adalah 0 dan derajat ruptur perineum tertinggi adalah 2 .

\section{Tabel 3 Derajat ruptur perineum Setelah Dilakukan Pijat Perineum dan Supercrowning Pada Ibu Bersalin Primipara $(n=18)$}

\begin{tabular}{lccc}
\hline \multicolumn{1}{c}{ Intervensi } & $\begin{array}{c}\text { Mean } \\
\text { rank }\end{array}$ & $\begin{array}{c}\boldsymbol{\rho} \\
\text { value }\end{array}$ & $\mathbf{Z}$ \\
\hline Pijat Perineum & 12.33 & 0,000 & -3.782 \\
Supercrowning & 24.67 & & \\
\hline
\end{tabular}

Tabel 3 menunjukkan hasil dari 18 responden yang diberikan perlakuan pijat perineum nilai mean rank 12,33. Hasil dari 18 responden yang diberikan perlakuan supercrowning nilai mean rank 24,67. Hal ini menunjukkan bahwa nilai mean rank pijat perineum lebih sedikit artinya pijat perineum lebih efektif mencegah ruptur perineum dibandingkan dengan supercrowning. Hasil penelitian untuk perbedaan efektifitas pijat perineum dan supercrowning terhadap derajat ruptur perineum pada ibu bersalin primipara $\mathrm{P}$ value $0,000(<0,05)$ maka $\mathrm{Ha}$ diterima dan $\mathrm{Ho}$ ditolak artinya ada perbedaan efektifitas pijat perineum dan supercrowning terhadap derajat ruptur perineum pada ibu bersalin primipara.

\section{PEMBAHASAN}

Ruptur perineum merupakan robekan yang terjadi pada saat bayi lahir, baik secara spontan maupun dengan menggunakan alat atau tindakan. Upaya untuk mencegah ruptur perineumdapat dilakukan dengan beberapa upaya, salah satunya adalah dengan pijat perineum. Pemijatan perineum ini sebaiknya sudah dilakukan sejak 5 sampai 6 minggu sebelum hari $\mathrm{H}$ persalinan. Pemijatan dilakukan selama 2 minggu menjelang persalinan.(Ishak, 2012).

Hasil penelitian didukung penelitian Risza Choirunnisa, Suprihatin, Han HanTahun 2019. Hasil penelitian menunjukkanbahwa pada kelompok intervensi yang mengalami ruptur perineum lebih kecil yaitu 4 orang $(26,67 \%)$ dibandingkan dengan kelompok kontrol 10 orang $(66,67 \%)$, p value $0.028(<0.05)$ yang berarti terdapat pengaruh antara pijat perineum dengan kejadian ruptur perineum.(Risza, 2019)

Hasil penelitian dapat diketahui bahwa tingkat ruptur dari 18 responden pada kelompok yang diberi perlakuan supercrowning nilai median adalah 1.00 dengan standar deviasi 0.669. Derajat ruptur perineum terendah adalah 0 dan derajat ruptur perineum tertinggi adalah 2 .

Pencegahan ruptur perineum dapat dilakukan juga dengan supercrowning. Hal ini karena adanya distensi lambat yang dapat mengurangi traumatic. Supercrowning merupakan salah satu metode melindungi perineum dengan memperlambat lahirnya kepala dengan sedikit memperpanjang kala II 
selama satu atau dua kontraksi.(Paula Veigendova,2017).

Hasil penelitian didukung penelitian $F$. Surayniwaty, Yuni Kusmiyati, Asmar Yetti Zein Tahun 2014. Hasil penelitian pada sampel 30 subjek, dibagi 2 kelompok yaitu 15 perlakuan (teknik supercrowning) dan 15 kontrol (teknik standart APN), kejadian ruptur perineum pada teknik supercrowning lebih kecil dibandingkan teknik standar APN dengan $p$ value $=0,03$ $(\alpha=0,05)$ yang membuktikan bahwa ada pengaruh teknik supercrowning terhadap kejadian ruptur perineum pada primipara. Teknik supercrowning merupakan factor protektif terhadap terjadinya ruptur perineum. (F.Surayniwaty, 2014)

Hasil penelitian menunjukkan bahwa ada perbedaan efektifitas pijat perineum dan supercrowning terhadap derajat ruptur perineum pada ibu bersalin primipara, dengan selisih nilai mean rank 12,33 pada kelompok yang diberikan perlakuan pijat perineum dan pada kelompok yang diberikan perlakuan supercrowning nilai mean rank 24,67. Nilai mean rank pijat perineum lebih sedikit dibandingkan mean rank supercrowning artinya derajat ruptur perineum pada pijat perineum lebih sedikit sehingga pijat perineum lebih efektif untuk menurunkan derajat ruptur perineum .

Pijat perineum lebih efektif untuk mencegah ruptur perineumkarena pijat perineum dilakukan beberapa minggu sebelum persalinan yaitu dilakukan mulai usia kehamilan 36 minggu secara kontinyu5x dalam seminggu. Hal ini akan mengakibatkan perubahan positif pada daerah perineum sehingga perineum menjadi elastis, fleksible dan lentur. Dengan demikian kejadian ruptur perineumdapat diminimalisir atau bahkan tidak ruptur sama sekali. Sedangkan upaya pencegahan ruptur perineumdengan supercrowning dilakukan secara mendadak hanya pada kala 2 persalinan yang masih memungkinkan terjadinya derajat ruptur perineum yang lebih tinggi dibandingkan dengan pijat perineum.
Pijat perineum dapat menciptakan rasa rilkes dan memberikan ketenangan pada ibu,menyiapkan mental ibu terhadap tekanan dan regangan pada perineum di kala kepala bayi akan keluar.(Ishak, 2012)

Hasil penelitian ini didukung oleh penelitian Wewet Savitri, Ermawati, dan Elda Yusefni tahun 2014. Hasil penelitian sebanyak 28 responden menunjukkan bahwa kejadian ruptur perineum pada kelompok intervensi setelah dilakukan pemijatan perineum hanya 3 orang $(21,4 \%)$, sementara pada kelompok kontrol kejadian ruptur perineum10 orang $(71,4 \%)$ dengan $p$ value $0,02(<0,05)$ menunjukkan ada pengaruh pemijatan perineum pada primigravida terhadap kejadian ruptur perineum pada saat persalinan antara kelompok intervensi dan kelompok control (Wewet Savitri, 2014)

Keterbatasan dalam penelitian ini terdapat pada pelaksanaan supercrowning pada 1 responden (1\%) dimana responden tidak maksimal melakukan supercrowning, pada saat kepala crowning responden sudah berusaha berhenti meneran dan bernafas pendek-pendek tetapi tidak sampai hingga kepala bayi lahir seluruhnya karena responden sudah tidak bisa menahan keinginan meneran dan ingin agar bayinya segera lahir.

\section{KESIMPULAN DAN SARAN}

Ada perbedaan efektifitas pijat perineum dan supercrowning terhadap derajat ruptur perineum pada ibu bersalin primipara. Pijat Perineum lebih efektif mencegah terjadinya ruptur perineum dibandingkan dengan supercrowning. Puskesmas melalui bidannya diharapkan menerapkan pijat perineum pada ibu hamil untuk mencegah ruptur perineum pada ibu bersalin primipara. Pada penelitian selanjutnya diharapkan dapat meneliti tentang faktor-faktor yang dapat mencegah terjadinya ruptur perineum yang belum diteliti seperti kegel exercise atau mengkombinasikan pijat perineum dengan supercrowning. 


\section{REFERENSI}

Eka Puspita, Sari, Kurnia Dwi Rimandini. (2014). Asuhan Kebidanan pada Persalinan, Cetakan 1. Jakarta : Trans Info Medika

Ishak,S. Ft Physio.(2012). Buku Petunjuk Pelaksanaan Massage Perineum pada Ibu Hamil

Jay Goldberg, MD and Carmen Sultana, MD. Preventing Perineal Lacerations During Labor. [Diakses tanggal 5 Mei 2019].

https://www.contemporaryobgyn.net/obst etrics-gynecology-womens-

health/preventing-perineal-lacerationsduring-labor

Paula Veigendova. (2015). Care of Woman With Birth Injury. Bachelor Thesis.

Profil Kesehatan Provinsi Jawa Tengah, 2018 [Diakses tanggal 6 Mei 2019] http://dinkesjatengprov.go.id/v2018/doku men/profil 2018/mobile/index.html.

Reeder Sharon, Martiin Leonide\& Griffin D. (2012). Keperawatan maternitas Kesehatan Wanita, Bayi, \& Keluarga. Volume 1 Jakarta : EGC.
Rizsa Choirunnisa, Suprihatin, Han Han, 2019. Pengaruh Pijat Perineum Terhadap Kejadian Ruptur perineum Pada lbu Bersalin Primipara di BPM Ny. I Cipageran Cimahi Utara, Kota Cimahi, Jawa Barat.

Sadli, S, 2010. Pemikiran Kajian tentang Perempuan. Jakarta : PT Kompas Media Nusantara.

Surayniwaty, Yuni Kusmiyati, Asmar Yetti Zein 2014. Pengaruh Tehnik Supercrowning terhadap Kejadian Ruptur perineum pada Primipara

Unicef. (2015). Estimates of Maternal Mortality Ratio (MMR : Maternal Death per 100.000 Live Births) 1990-2015.

Wewet Savitri, Ermawati dan Elda Yusefni.(2014).Pengaruh Pemijatan Perineum pada Primigravida terhadap Kejadian Ruptur perineum Saat Persalinan di Bidan Praktek Mandiri di Kota Bengkulu.

Yuliawati Yetty Anggraini. (2013). Hubungan Riwayat Pre Eklampsia, Retensio Plasenta, Atonia Uteri dan Laserasi Jalan Lahir Dengan Kejadian Perdarahan Post Partum pada Ibu Nifas, Lampung 